CLINICAL STUDY

\title{
Retinoic acid receptor and retinoid $X$ receptor subtype expression for the differential diagnosis of thyroid neoplasms
}

\author{
Hendrieke C Hoftijzer ${ }^{1}$, Ying Y Liu ${ }^{1}$, Hans Morreau ${ }^{2}$, Ton van Wezel ${ }^{2}$, Alberto M Pereira ${ }^{1}$, Eleonora P M Corssmit ${ }^{1}$, \\ Johannes A Romijn ${ }^{1}$ and Johannes W A Smit ${ }^{1}$ \\ Departments of ${ }^{1}$ Endocrinology and Metabolic Diseases C4-R and ${ }^{2}$ Pathology, Leiden University Medical Centre, PO Box 9600, 2300 RC Leiden, \\ The Netherlands \\ (Correspondence should be addressed to J W A Smit; Email: jwasmit@lumc.nl)
}

\begin{abstract}
Background: Although differential expression of retinoic acid receptor (RAR) subtypes between benign and malignant thyroid tissues has been described, their diagnostic value has not been reported. Aim: To investigate the diagnostic accuracy of RAR and retinoid X receptor (RXR) subtype protein expression for the differential diagnosis of thyroid neoplasms.

Methods: We used a tissue array containing 93 benign thyroid tissues (normal thyroid, multinodular goiter, and follicular adenoma (FA)) and 77 thyroid carcinomas (papillary thyroid carcinoma (PTC), follicular thyroid carcinoma, and follicular variant of PTC (FVPTC)). Immunostaining was done for RAR and RXR subtypes. Staining was analyzed semiquantitatively based on receiver operating curve analyses and using hierarchical cluster analysis.

Results: We found increased expression of cytoplasmic (c) RARA, cRARG, cRXRB and decreased expression of nuclear (n) RARB, nRARG, and nRXRA in thyroid carcinomas compared with benign tissues. We found three proteins differently expressed between FA and FTC and five proteins differentially expressed between FA and FVPTC, with high diagnostic accuracies. Using cluster analysis, the combination of negative staining of membranous RXRB and positive staining for cRXRB had a high positive predictive value $(98 \%)$ for malignant thyroid disease, whereas the combination of positive nRXRA and negative cRXRB staining had a high predictive value (91\%) for benign thyroid lesions.

Conclusion: We conclude that differences in RAR and RXR subtype protein expression may be valuable for the differential diagnosis of thyroid neoplasms. The results of this study and especially the value of cluster analysis have to be confirmed in subsequent studies.
\end{abstract}

European Journal of Endocrinology $160631-638$

\section{Introduction}

The microscopical distinction between benign and malignant neoplastic thyroid nodules by conventional histology is often difficult as these lesions may share overlapping histological characteristics. Therefore, it is important to identify new markers to distinguish benign from malignant thyroid tumors. In recent years, several immunohistochemical markers have been studied to improve the differential diagnosis of thyroid lesions, using both candidate markers and unbiased approaches (1-12).

The expression of retinoid receptors may be interesting for the differentiation between benign and malignant thyroid tissues. Retinoids are important for growth, differentiation, and morphogenesis in vertebrates (13). Retinoids are derivatives of vitamin A (i.e. retinol). Retinoid receptors belong to the family of nuclear receptors and can be distinguished in retinoic acid receptors (RAR) and retinoid X receptors
(RXR). According to the literature, retinoid receptors appear to be differentially expressed in benign and malignant thyroid tissues, the general picture being decreased expression of retinoid receptor subtypes in thyroid cancer (Table 1) (14-20), which may also have therapeutic implications $(17,18,21-23)$. However, in these publications on retinoid receptor expression in thyroid lesions, the question whether retinoid receptor expression could be used for the differential diagnosis of thyroid neoplasms was not addressed, probably because most studies included relatively small number of patient samples or the studies included only a subset of retinoid receptors (Table 1).

We, therefore, decided to study the diagnostic value of RAR and RXR subtype expression in benign and malignant thyroid tissues, using receiver operating curve (ROC) analyses as well as hierarchical cluster analysis (12). In addition, we also studied the prognostic value of RAR expression for relapse-free survival. 


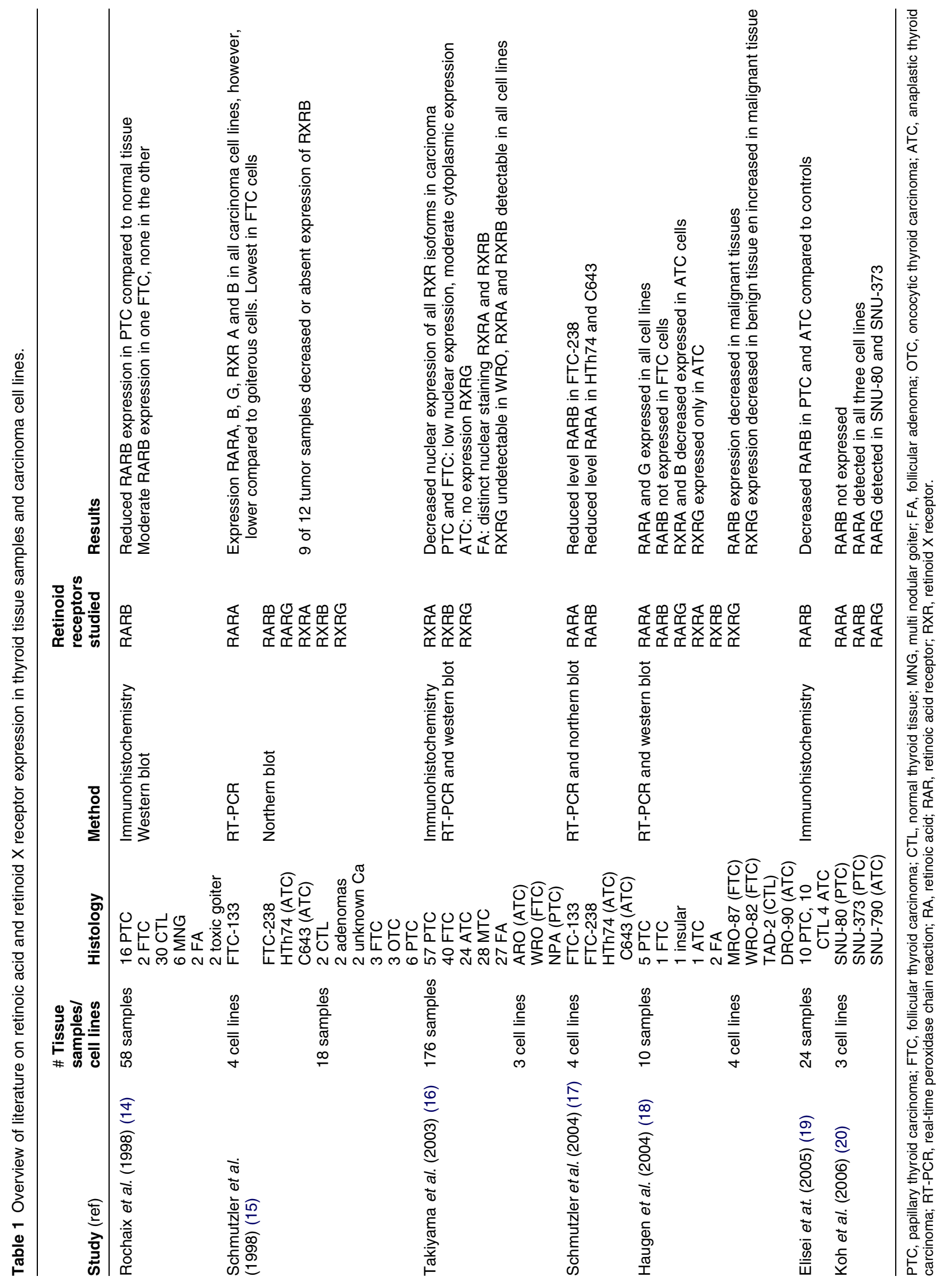




\section{Materials and methods}

\section{Thyroid tissues}

We obtained one hundred and seventy histological samples from surgically removed thyroid lesions representing five different histological thyroid disorders and adjacent thyroid normal tissue from the archive of the Department of Pathology of the Leiden University Medical Centre. We selected 93 benign thyroid tissues (normal $n=64$, multinodular goiter $n=16$, follicular adenoma (FA) $n=13$ ), and 77 non-medullary thyroid carcinomas (papillary thyroid carcinoma (PTC) $n=53$, follicular thyroid carcinoma (FTC) $n=13$ and follicular variant of PTC (FVPTC) $n=11$ ). All original histological diagnoses were reviewed by two independent observers. Given the variability in phenotype of follicular lesions, only microfollicular FA and widely invasive FTC's were included on which both observers agreed. Likewise, we only included encapsulated FVPTC tumors with a typical PTC nuclear pattern on which both observers agreed.

\section{Tissue microarray}

Formalin-fixed, paraffin-embedded blocks routinely prepared from surgical specimens of thyroid tumors were selected for this study. Representative areas containing tumor or adjacent normal tissue were identified by a pathologist. Triplicate tissue cores with a diameter of $0.6 \mathrm{~mm}$ were taken from each specimen (Beecher Instruments, Silver Springs, MD, USA) and arrayed on a recipient paraffin block, using standard procedures (24).

\section{Immunohistochemistry methods}

Four micrometer consecutive tissue sections were cut from each arrayed paraffin block and prepared on pathological slides. The sections were deparaffinized in xylene followed by $0.3 \%$ hydrogen peroxide in methanol at room temperature for $20 \mathrm{~min}$ to block endogenous peroxidase.
After rehydration, antigen retrieval was performed by microwave treatment in $0.001 \mathrm{M}$ citrate buffer ( $\mathrm{pH}$ 6.0). The sections were incubated with the following primary antibodies against RAR and RXR subtypes: anti-RARA monoclonal antibody 9A9A6, dilution 1:3000; antiRARB monoclonal antibody 8B10B2, dilution 1:200; anti-RARG monoclonal antibody. 4G-7A11, dilution 1:350; anti-RXRA monoclonal antibody 4RX3A2, dilution 1:1000 (all gifts of Dr C Rochette-Egly, IGBMC, Illkirch, France), anti-RXRB polyclonal antibody sc-831, dilution 1:650 (Santa Cruz Biotechnology, Santa Cruz, CA, USA); anti-RXRG polyclonal antibody sc-555, dilution 1:500 (Santa Cruz). Sections were incubated overnight at room temperature with the primary antibodies, dissolved in PBS with $1 \%$ bovine serum albumin. Subsequently, the sections were incubated for $30 \mathrm{~min}$ with either the biotinylated rabbit-anti-mouse conjugate, dilution 1:200 or goat-anti-rabbit, dilution 1:400 (DakoCytomation, Glostrup, Denmark), followed by incubation for $30 \mathrm{~min}$ with the streptavidin-biotin-peroxidase conjugate. This step was performed by 10-min incubation with 3,3'diaminobenzidinetetrachloride substrate in a buffered $0.05-\mathrm{M}$ Tris/ $\mathrm{HCl}(\mathrm{pH} 7.6)$ solution containing $0.002 \%$ hydrogen peroxide. Negative controls were stained with the primary antibody omitted. The sections were counterstained with hematoxylin.

\section{Immunohistochemical scoring}

A semiquantitative assessment of immunohistochemical scoring was performed including both the intensity of staining and the percentage of positive cells. The percentage of cells with positive staining was scored as follows: >0-20\%: ' 1 ', > 20-50\%: ' 2 ', > $>0-70 \%$ : '3', and $>70-100 \%$ ' 4 '. The staining intensity was scored as faint: ' 1 ', intermediate: '2', and intense: ' 3 '. Scores for proportion of positive cells and intensity were multiplied. Nuclear, cytoplasmic, and membranous staining was scored independently. The total score per sample therefore ranged from 0 to 12 . Score results for triplicate samples were averaged.

Table 2 Results of retinoid receptor subtype immunohistochemistry.

\begin{tabular}{lcccccc}
\hline & Normal $(n=64)$ & $\begin{array}{c}\text { Multi nodular } \\
\text { goiter }(n=16)\end{array}$ & $\begin{array}{c}\text { Follicular ade- } \\
\text { noma }(n=13)\end{array}$ & FTC $(n=13)$ & FVPTC $(n=11)$ & PTC $(n=53)$ \\
\hline Nuclear RARA & $4.47 \pm 1.98$ & $4.06 \pm 1.46$ & $4.88 \pm 1.67$ & $6.02 \pm 3.71$ & $1.12 \pm 2.39$ & $2.56 \pm 2.43$ \\
Cytoplasm RARA & $0.0 \pm 0.0$ & $0.0 \pm 0.0$ & $0.0 \pm 0.0$ & $2.43 \pm 4.47$ & $1.67 \pm 2.42$ & $1.21 \pm 2.47$ \\
Nuclear RARB & $8.53 \pm 2.20$ & $8.62 \pm 1.42$ & $8.63 \pm 2.21$ & $5.62 \pm 3.37$ & $5.78 \pm 3.12$ & $6.21 \pm 3.18$ \\
Nuclear RARG & $4.56 \pm 2.59$ & $3.17 \pm 1.4$ & $3.17 \pm 2.26$ & $1.61 \pm 1.58$ & $0.85 \pm 1.92$ & $2.00 \pm 2.63$ \\
Cytoplasmic RARG & $0.0 \pm 0.0$ & $0.0 \pm 0.0$ & $0.55 \pm 1.81$ & $1.78 \pm 3.541$ & $0.54 \pm 1.80$ & $0.93 \pm 2.58$ \\
Nuclear RXRA & $2.29 \pm 2.00$ & $2.27 \pm 2.03$ & $2.64 \pm 2.60$ & $0.44 \pm 0.12$ & $0.00 \pm 0.00$ & $0.37 \pm 1.10$ \\
Nuclear RXRB & $0.71 \pm 1.62$ & $0.36 \pm 1.21$ & $0.0 \pm 0.0$ & $0.00 \pm 0.00$ & $0.30 \pm 0.95$ & $0.32 \pm 1.33$ \\
Cytoplasmic RXRB & $0.07 \pm 0.53$ & $0.0 \pm 0.0$ & $2.18 \pm 4.85$ & $5.99 \pm 4.89$ & $2.68 \pm 4.54$ & $6.80 \pm 4.55$ \\
Membranous RXRB & $1.66 \pm 2.06$ & $3.34 \pm 2.05$ & $4.53 \pm 2.69$ & $1.88 \pm 1.88$ & $1.41 \pm 2.84$ & $0.92 \pm 2.20$ \\
\hline
\end{tabular}

Scoring method: the percentage of cells with positive staining was scored: $>0-20 \%$ : ' 1 ', $>20-50 \%$ : '2', > $>50-70 \%$ : ' 3 ', and $>70-100 \%$ ' 4 '. The intensity was scored as faint: ' 1 ', intermediate: ' 2 ', and intense: ' 3 '. These scores were multiplied. Score results for triplicate samples were averaged. Distinctive scores were categorized according to nuclear, cytoplasm and membranous staining patterns. Data are mean \pm S.D. RAR, retinoic acid receptor; RXR, retinoid X receptor. 


\section{Statistical analyses}

Statistical analyses were performed using SPSS 14.0 (SPSS Inc., Chicago, IL, USA). Initially, staining scores for every individual antibody were expressed as mean \pm s.D. per histological category (Table 2). The next step was the analysis of differences in staining scores for each antibody between malignant versus benign tissues, malignant versus normal tissues, FA versus FTC and FA versus FVPTC using the MannWhitney test. For each differentially expressed antibody between two histological categories, the optimal cut-off value for the distinction between the two categories was determined by receiver operating characteristic (ROC) analysis. In theory, this could give different cut-off values for one antibody for different comparisons. Only antibodies with sensitivities and specificities above $70 \%$ were included in further analyses. In addition to the individual protein markers, the analysis of the diagnostic accuracy of panels of antibodies was performed using hierarchical clustering analysis of tissue microarray data using Cluster and TreeView (Cluster and TreeView 2.11; Eisen Lab, University of California at Berkeley, CA, USA) $(12,25)$. Input for these analyses was the individual staining score per sample for each antibody. A $P$ value of $<0.05$ was considered significant.

\section{Results}

\section{RAR and RXR expression in thyroid lesions: benign versus malignant}

The scores for expression of RAR and RXR receptor subclasses are shown in Table 2. Benign tissue samples had an overall lower expression of cytoplasmic RARA (cRARA), cytoplasmic RARG (cRARG), and cytoplasmic RXRB (cRXRB) and a higher expression of nuclear RARA (nRARA), nuclear (n) RARB, nuclear RARG (nRARG) and nuclear RXRA (nRXRA) compared with malignant tissues. FA scored particularly high for nuclear RXRA (nRXRA) and low for nuclear RXRB (nRXRB) expression. FVPTC also had a very low expression of nRXRB. RXRG staining did not reveal a positive result in all thyroid tissues, and was excluded from further analyses.

Figure 1 shows the differences in expression patterns for different categories of thyroid tissues. All RAR and RXR subtypes appeared to be differentially expressed between malignant thyroid lesions and normal thyroid tissue.

\section{RAR and RXR expression in thyroid lesions: follicular lesions}

The differentiation between follicular lesions (FA, FTC, and FVPTC) is difficult. Therefore, we compared these subgroups separately. FTC had a significantly lower expression of nRARB, nRXRA, and mRXRB compared with FA. FVPTC had a significantly lower expression of nRARA, nRARB, nRARG, nRXRA, and mRXRB compared with FA (Fig. 1).
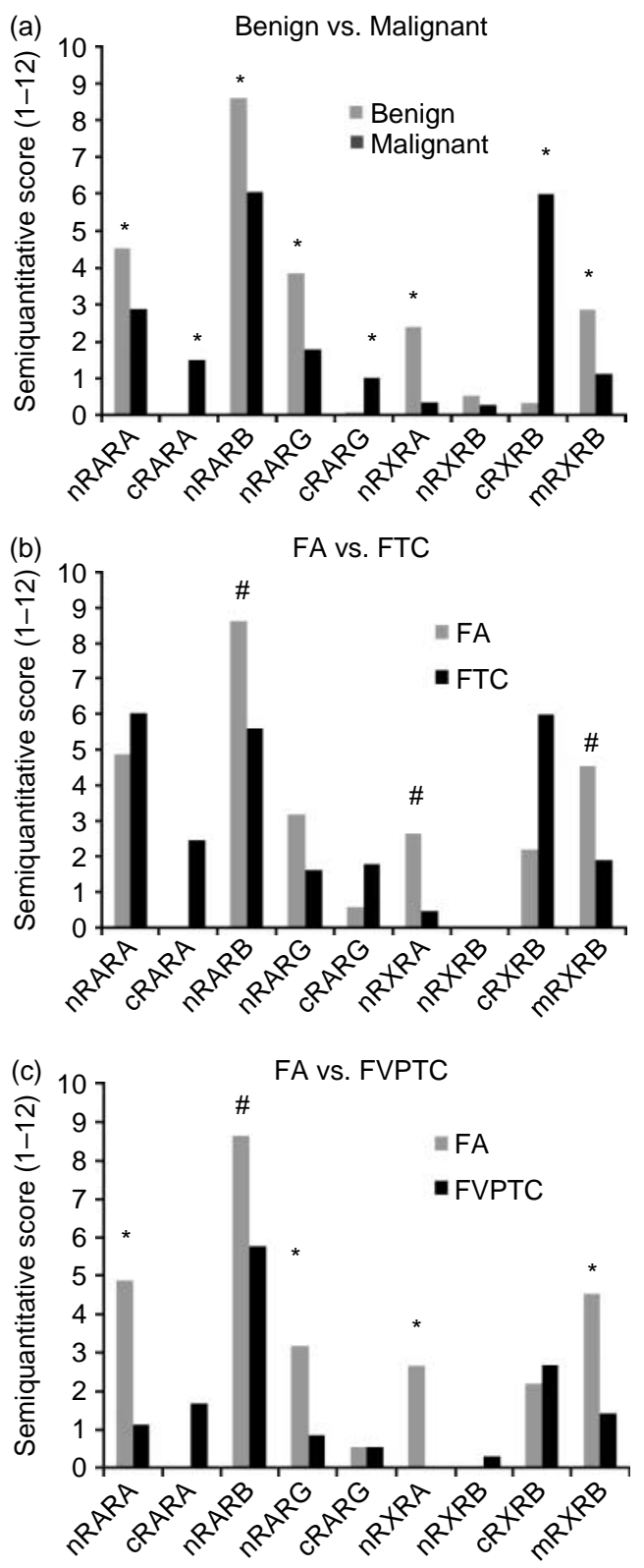

Figure 1 (A) Immunostaining of RAR and RXR subtype antibodies in normal, benign, and malignant thyroid lesions. Immunohistochemistry scores were expressed semi-quantitatively (for explanation, see text). Data are expressed as mean \pm s.D. Comparisons between (A) benign and malignant; (B) follicular adenoma (FA) and follicular thyroid carcinoma (FTC), and (C) follicular adenoma and follicular variant of papillary carcinoma (FVPTC) were performed with the Mann-Whitney test. ${ }^{*} P<0.005$; \# $P<0.05 ; n=$ nuclear; $\mathrm{c}=$ cytoplasmic; $\mathrm{n}=$ nuclear; RAR $=$ Retinoic Acid Receptor; $\mathrm{RXR}=$ Retinoid $\mathrm{X}$ Receptor 


\section{ROC analyses}

For each differentially expressed antibody between two categories, the optimal cut-off values for the distinction between the two histological classes were determined by ROC analysis. Only antibodies with sensitivities and specificities above $70 \%$ were used for further analyses (Table 3). Comparison of the expression between benign and malignant thyroid tissues revealed sensitivities and specificities $>70 \%$ for nRXRA, cRXRB, and mRXRB, the highest sensitivity (89\%) and specificity (96\%) for nuclear RXRA (Table 3). NRXRA and cRXRB also discriminated reasonably between malignant and normal thyroid tissues.

In the comparison between FA and FTC, nRARB, nRARA, cRXRB, and mRXRB had sensitivities and specificities above $70 \%$, the highest sensitivity for FTC found for nRARA (85\%) and the highest specificity for nRARB (91\%; Table 3).

In the comparison between FA and FVPTC, nRARB, nRARG, nRARA, nRXRA and mRXRB had sensitivities and specificities above $70 \%$. The highest sensitivity for FVPTC was found for nRXRA (100\%) and the highest specificities for both nuclear nRARA (91\%) and nRARG (91\%; Table 3).

\section{Hierarchical cluster analysis}

To identify the optimal combinations of RAR and RXR subtype expression for the differential diagnosis of thyroid neoplasms, we performed an unsupervised hierarchical cluster analysis, the results of which are shown in Fig. 2 and Table 4. We found that 98\% of thyroid lesions in cluster 2 (negative staining of mRXRB and positive staining for cRXRB) were malignant, whereas $91 \%$ of the lesions in cluster 4 (positive staining for nRXRA and a negative staining for cRXRB) were benign. The diagnostic parameters are summarized in Table 4.

In general, the follicular lesions did not cluster separately, but we found that only one FA was present in cluster 2 (high positive predictive value for malignancy), whereas in cluster 4 (high positive predictive value for benign lesions) only one FTC was present (Fig. 3).

\section{Discussion}

The present study was performed to evaluate the diagnostic value of the expression of RAR and RXR subtypes in a large panel of thyroid neoplasms. To our knowledge, the diagnostic value of RAR and RXR receptor expression for the differential diagnosis of thyroid neoplasms has not been published before (1420). Our study also differed from earlier ones with regard to the identification of optimal semiquantitative cut-off levels using ROC analyses and hierarchical cluster analysis.

In general, we found an increased expression of cRARA, cRARG, cRXRB, and a decreased expression of nRARB, nRARG, and nRARA in thyroid carcinomas compared with benign thyroid tissue. The most challenging pathological differential diagnosis is between FA, FTC, and FVPTC. We found three proteins differentially expressed between FA and FTC and five proteins differentially expressed between FA and FVPTC. In the comparison between FA and FTC the highest sensitivity for FTC was found for nRARA and the highest specificity for nRARB. In the comparison between FA and FVPTC, the highest sensitivity for FVPTC was found for nRXRA and the highest specificities for nRARA and nRARG.

Table 3 Diagnostic value of RAR and RXR differentially expressed in thyroid tissues with sensitivity and specificity above $70 \%$.

\begin{tabular}{|c|c|c|c|c|c|c|}
\hline & \multicolumn{3}{|c|}{ Malignant versus benign } & \multicolumn{3}{|c|}{ Malignant versus normal } \\
\hline & Cut-off level ${ }^{a}$ & $\begin{array}{l}\text { Sensitivity for } \\
\text { malignancy (\%) }\end{array}$ & $\begin{array}{l}\text { Specificity for } \\
\text { malignancy (\%) }\end{array}$ & Cut-off level ${ }^{a}$ & $\begin{array}{l}\text { Sensitivity for } \\
\text { malignancy (\%) }\end{array}$ & $\begin{array}{l}\text { Specificity for } \\
\text { malignancy (\%) }\end{array}$ \\
\hline \multirow{5}{*}{$\begin{array}{l}\text { Nuclear RARB } \\
\text { Nuclear RXRA } \\
\text { Cytoplasmic RXRB } \\
\text { Membranous RXRB }\end{array}$} & & & & $<8.5$ & 72 & 80 \\
\hline & $<1$ & 89 & 96 & $<1$ & 89 & 75 \\
\hline & $>1$ & 71 & 96 & $>1$ & 71 & 89 \\
\hline & \multicolumn{3}{|c|}{ FTC versus FA } & \multicolumn{3}{|c|}{ FVPTC versus FA } \\
\hline & Cut-off level $^{\mathrm{a}}$ & $\begin{array}{l}\text { Sensitivity for } \\
\text { FTC }(\%)\end{array}$ & $\begin{array}{l}\text { Specificity for } \\
\text { FTC }(\%)\end{array}$ & Cut-off level ${ }^{a}$ & $\begin{array}{l}\text { Sensitivity for } \\
\text { FVPTC (\%) }\end{array}$ & $\begin{array}{l}\text { Specificity for } \\
\text { FVPTC (\%) }\end{array}$ \\
\hline Nuclear RARA & $<1$ & 85 & 80 & $<3$ & 92 & 91 \\
\hline Nuclear RARB & $<8$ & 73 & 91 & $<8$ & 91 & 82 \\
\hline Cytoplasmic RXRB & $>2$ & 71 & 82 & & & \\
\hline Membranous RXRB & $<4$ & 82 & 75 & $<1$ & 82 & 82 \\
\hline
\end{tabular}

Benign thyroid tissues, multinodular goiter, follicular adenoma and normal; RAR, retinoic acid receptor; RXR, retinoid $X$ receptor.

abtained by ROC analyses of semi-quantitative immunohistochemistry scores. 


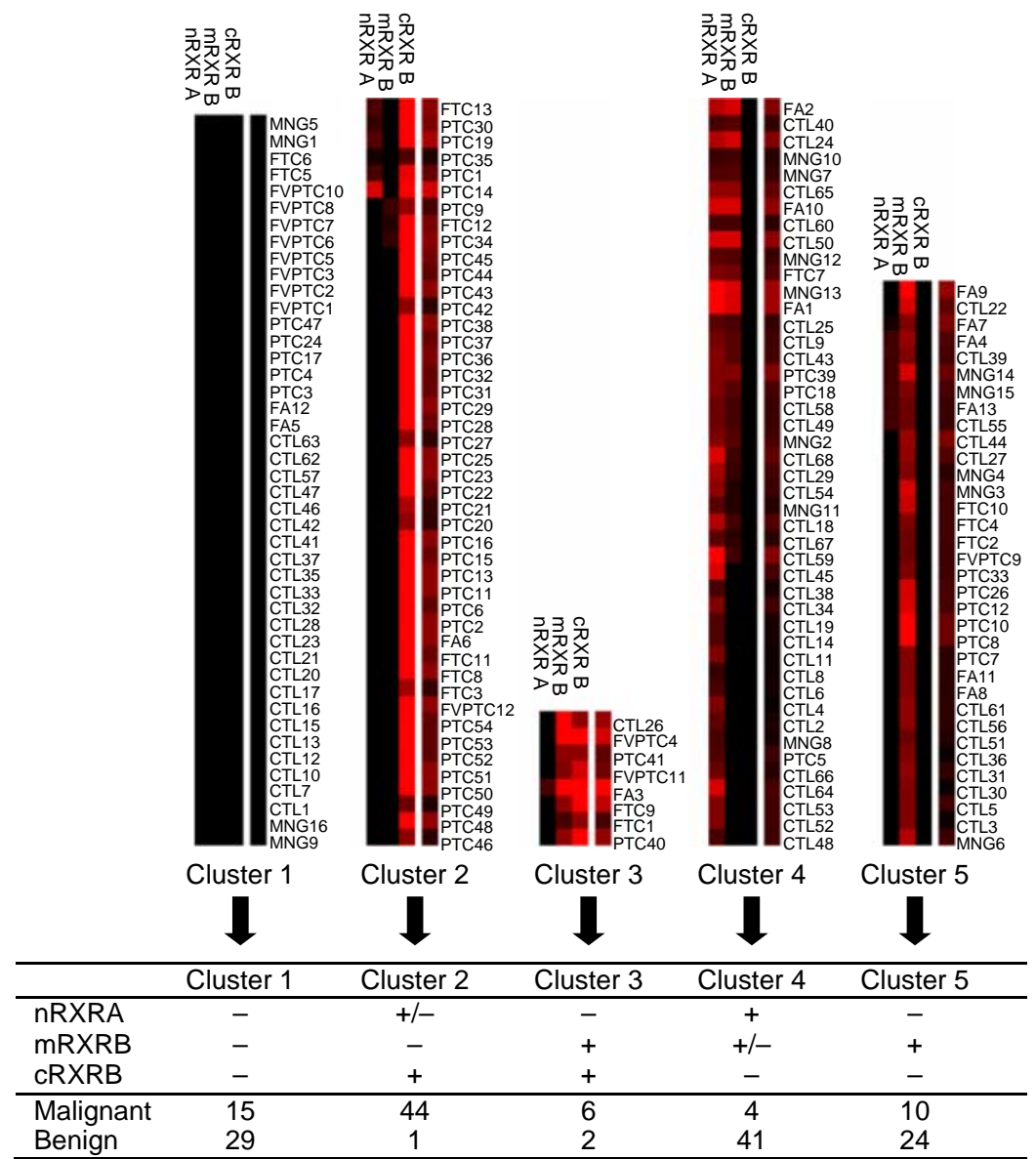

Figure 2 Hierarchical cluster analyses using RAR and RXR subtype antibodies in thyroid tissues. Nuclear RXRA, cytoplasmic, and membranous RXRB were identified as the best predictors of benign or malignant thyroid lesions. The absence of membranous ( $m$ ) RXRB and the presence of cytoplasmic (c) RXRB had a high positive predictive value for malignancy (98\%, cluster 2). The presence of nuclear ( $\mathrm{n}$ ) RXRA and absence of cytoplasmic RXRB had a high positive predictive value for benign lesions (91\%, cluster 4). CTL, normal thyroid; HP, hyperplasia; FA, follicular adenoma; FTC, follicular thyroid carcinoma; PTC, papillary thyroid carcinoma; FVPTC, follicular variant PTC. Full colour version of this figure available via http://dx.doi.org/10.1530/EJE-08-0812.
Some of these observations are in line with other studies that investigated RAR and/or RXR expression in thyroid tissue samples (Table 1). Rochaix et al. (14) (Immunohistochemistry), Haugen et al. (18) (RT-PCR), and Elisei et al. (19) (RT-PCR) also found reduced RAR $\beta$ expression in PTC, compared with normal tissue. Rochaix et al. (14) only investigated two FTC samples of which one sample showed moderate RARB expression and the

Table 4 Diagnostic value of combinations of retinoid receptor staining for benign vs. malignant thyroid lesions, based on hierarchical cluster analysis.

\section{Combination mRXRB - Combination not \\ and CRXRB $+\quad$ present $\quad$ Total}

(a) Diagnostic value of combinations of retinoid receptor staining for benign versus malignant thyroid lesions, based on cluster 2 in hierarchical cluster analysis

Malignant 44

Benign

14 (FA)

Total

45

35

$96 \quad 98$

PPV malignancy $=98 \% \quad$ NPV malignancy $=72 \% \quad$ LR malignancy 56

\section{Combination nRXRA + Combination not and CRXRB - $\quad$ present}

(b) Diagnostic value of $n R X R \alpha$ and cRXR $\beta$ staining for benign versus malignant thyroid lesions, based on cluster 4 in hierarchical cluster analysis

Benign

Malignant

42

Total

$\begin{array}{lll}42 & 56 & 98 \\ 4(3 \mathrm{PTC} / 1 \mathrm{FTC}) & 75 & 79 \\ 46 & 130 & 176 \\ \text { PPV benign }=91 \% & \text { NPV benign }=57 \% & \end{array}$

98

176

LR 8.6

RAR, retinoic acid receptor; RXR, retinoid X receptor; PPV, positive predicting value; NPV, negative predicting value; LR, likelihood. 
RARA

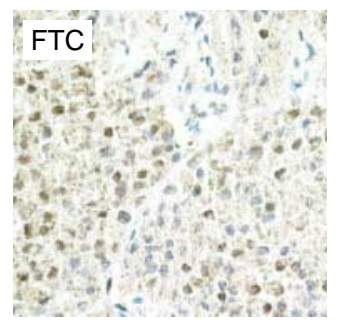

$R A R B$

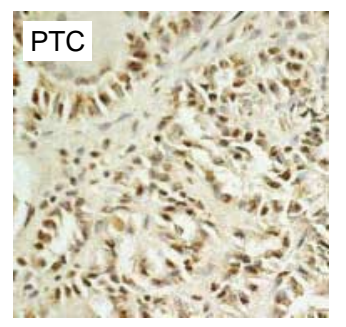

$R A R G$

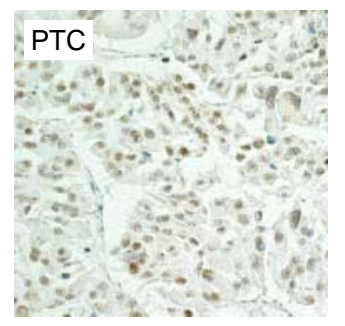

$R X R B$

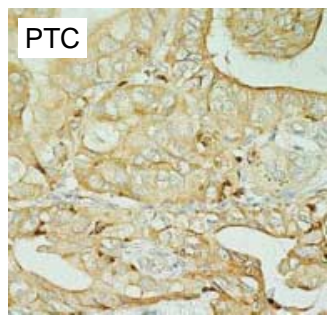

$R X R A$

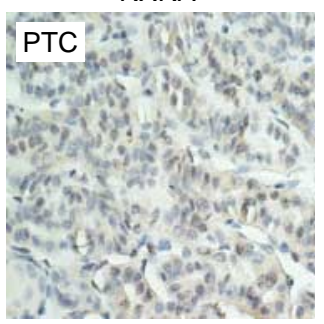

Figure 3 Tissue samples of primary tumors from patients with metastatic DTC. Immunohistochemistry was performed with antiRAR and RXR antibodies as indicated in the Patients and methods. Magnification was $200 \times$. All samples showed positive staining. For RXRB cytoplasmic staining is shown, as in most patients with DTC. Full colour version of this figure available via http://dx.doi.org/10.1530/EJE-08-0812.

other did not. Our finding of higher nuclear and lower cytoplasm expression of RARG in malignant thyroid tissues was not reported before. Nuclear RXRA expression was low or absent in thyroid carcinomas in our study. This finding is confirmed by a paper by Takiyama et al. (16). We did not find positive RXRG staining in thyroid tissues, which is unexpected, given the results of Haugen et al. by western blot (18).

There are two studies on RXRB expression in thyroid neoplasms $(15,16)$. They both found decreased or absent expression of RXRB in carcinomas. One of these studies, however, (15) used RT-PCR and contained only 12 human thyroid carcinoma samples. In our study, we differentiated between nuclear, cytoplasmic, and membranous staining. The only study that also differentiated between nuclear and cytoplasm staining pattern, only investigated RXR isoform expression (16).

We performed a cluster analysis including all studied tissues and antibodies. Our findings showed that the combination of negative staining of mRXRB and a positive staining for $\mathrm{CRXRB}$ had a high accuracy for the detection of malignant thyroid tissues, whereas the combination of a positive staining for nRXRA and a negative staining for cRXRB was present in most benign tissues.

There are some limitations to our study. Although, we were able to distinguish between follicular lesions, the number of follicular lesions was relatively small. Therefore, additional studies should be performed with larger numbers of follicular lesions, also including histological subtypes of follicular lesions. Moreover, the findings of our study and the clinical usefulness of hierarchical cluster analysis have to be validated in subsequent studies and most importantly in cytological preparations. Also, other difficult-to-classify thyroid neoplasms such as minimally invasive follicular carcinomas as well as FA subclasses should be included in subsequent studies. The biological mechanisms responsible for the differential expression of RAR and RXR between thyroid tissues also remain to be elucidated. In conclusion, differences in RAR and RXR subtype protein expression as studied by immunohistochemistry may be of additional value in the differential diagnosis of thyroid neoplasms.

\section{Declaration of interest}

There is no conflict of interest that could be perceived as prejudicing the impartiality of the research reported.

\section{Funding}

This work was supported by the Dutch Councer Foundation KWF (grant number KWF 2001-2568).

\section{References}

1 Huang Y, Prasad M, Lemon WJ, Hampel H, Wright FA, Kornacker K, LiVolsi V, Frankel W, Kloos RT, Eng C, Pellegata NS \& de la Chapelle A. Gene expression in papillary thyroid carcinoma reveals highly consistent profiles. PNAS $20019815044-15049$.

2 Zhao J, Leonard C, Gemsenjager E, Heitz PU, Moch H \& Odermatt B. Differentiation of human follicular thyroid adenomas from carcinomas by gene expression profiling. Oncology Reports 2008 $19329-337$.

3 Zhao J, Leonard C, Brunner E, Gemsenjager E, Heitz PU \& Odermatt B. Molecular characterization of well-differentiated human thyroid carcinomas by cDNA arrays. International Journal of Oncology 200629 1041-1051.

4 Lubitz CC \& Fahey TJ III. Gene expression profiling of thyroid tumors - clinical applicability. Nature Clinical Practice. Endocrinology \& Metabolism $20062472-473$. 
5 Fryknas M, Wickenberg-Bolin U, Goransson H, Gustafsson MG, Foukakis T, Lee JJ, Landegren U, Hoog A, Larsson C, Grimelius L, Wallin G, Pettersson U \& Isaksson A. Molecular markers for discrimination of benign and malignant follicular thyroid tumors. Tumour Biology 200627 211-220.

6 Eszlinger M, Wiench M, Jarzab B, Krohn K, Beck M, Lauter J, Gubala E, Fujarewicz K, Swierniak A \& Paschke R. Meta- and reanalysis of gene expression profiles of hot and cold thyroid nodules and papillary thyroid carcinoma for gene groups. Journal of Clinical Endocrinology and Metabolism $2006 \mathbf{9 1}$ 1934-1942.

7 Fujarewicz K, Jarzab M, Eszlinger M, Krohn K, Paschke R, OczkoWojciechowska M, Wiench M, Kukulska A, Jarzab B \& Swierniak A. A multi-gene approach to differentiate papillary thyroid carcinoma from benign lesions: gene selection using support vector machines with bootstrapping. Endocrine-Related Cancer 200714 809-826.

8 Rosen J, He M, Umbricht C, Alexander HR, Dackiw AP, Zeiger MA \& Libutti SK. A six-gene model for differentiating benign from malignant thyroid tumors on the basis of gene expression. Surgery 2005138 1050-1056.

9 Stolf BS, Abreu CM, Mahler-Araujo MB, Dellamano M, Martins WK, de Carvalho MB, Curado MP, Diaz JP, Fabri A, Brentani H, Carvalho AF, Soares FA, Kowalski LP, Hirata R Jr \& Reis LF. Expression profile of malignant and non-malignant diseases of the thyroid gland reveals altered expression of a common set of genes in goiter and papillary carcinomas. Cancer Letters $2005 \mathbf{2 2 7} 59-73$.

10 Finley DJ, Lubitz CC, Wei C, Zhu B \& Fahey TJ III. Advancing the molecular diagnosis of thyroid nodules: defining benign lesions by molecular profiling. Thyroid 200515 562-568.

11 Wasenius VM, Hemmer S, Kettunen E, Knuutila S, Franssila K \& Joensuu H. Hepatocyte growth factor receptor, matrix metalloproteinase-11, tissue inhibitor of metalloproteinase-1, and fibronectin are up-regulated in papillary thyroid carcinoma: a cDNA and tissue microarray study. Clinical Cancer Research 20039 68-75.

12 Liu YY, Morreau H, Kievit J, Romijn JA, Carrasco N \& Smit JW. Combined immunostaining with galectin-3, fibronectin-1, CITED1, Hector Battifora mesothelial-1, cytokeratin-19, peroxisome proliferator-activated receptor-\{gamma\}, and sodium/iodide symporter antibodies for the differential diagnosis of non-medullary thyroid carcinoma. European Journal of Endocrinology $2008 \mathbf{1 5 8}$ 375-384.

13 Smith MA, Parkinson DR, Cheson BD \& Friedman MA. Retinoids in cancer therapy. Journal of Clinical Oncology 199210 839-864.

14 Rochaix P, Monteil-Onteniente S, Rochette-Egly C, Caratero C, Voigt JJ \& Jozan S. Reduced expression of retinoic acid receptor beta protein (RAR beta) in human papillary thyroid carcinoma: immunohistochemical and western blot study. Histopathology $199833337-343$.

15 Schmutzler C, Brtko J, Winzer R, Jakobs TC, Meissner-Weigl J, Simon D, Goretzki PE \& Kohrle J. Functional retinoid and thyroid hormone receptors in human thyroid-carcinoma cell lines and tissues. International Journal of Cancer $1998 \mathbf{7 6}$ 368-376.
16 Takiyama Y, Miyokawa N, Sugawara A, Kato S, Ito K, Sato K, Oikawa K, Kobayashi H, Kimura S \& Tateno M. Decreased expression of retinoid $\mathrm{X}$ receptor isoforms in human thyroid carcinomas. Journal of Clinical Endocrinology and Metabolism 2004 89 5851-5861.

17 Schmutzler C, Hoang-Vu C, Ruger B \& Kohrle J. Human thyroid carcinoma cell lines show different retinoic acid receptor repertoires and retinoid responses. European Journal of Endocrinology 2004150 547-556.

18 Haugen BR, Larson LL, Pugazhenthi U, Hays WR, Klopper JP, Kramer CA \& Sharma V. Retinoic acid and retinoid X receptors are differentially expressed in thyroid cancer and thyroid carcinoma cell lines and predict response to treatment with retinoids. Journal of Clinical Endocrinology and Metabolism $2004 \mathbf{8 9}$ 272-280.

19 Elisei R, Vivaldi A, Agate L, Ciampi R, Molinaro E, Piampiani P, Romei C, Faviana P, Basolo F, Miccoli P, Capodanno A, Collecchi P, Pacini F \& Pinchera A. All-trans-retinoic acid treatment inhibits the growth of retinoic acid receptor beta messenger ribonucleic acid expressing thyroid cancer cell lines but does not reinduce the expression of thyroid-specific genes. Journal of Clinical Endocrinology and Metabolism 200590 2403-2411.

20 Koh CS, Ku JL, Park SY, Kim KH, Choi JS, Kim IJ, Park JH, Oh SK, Chung JK, Lee JH, Kim WH, Kim CW, Cho BY \& Park JG. Establishment and characterization of cell lines from three human thyroid carcinomas: responses to all-trans-retinoic acid and mutations in the BRAF gene. Molecular and Cellular Endocrinology $2007264118-127$.

21 Havekes B, Schroder Van Der Elst JP, van der PG, Goslings BM, Romijn JA \& Smit JW. Beneficial effects of retinoic acid on extracellular matrix degradation and attachment behaviour in follicular thyroid carcinoma cell lines. Journal of Endocrinology $2000167229-238$.

22 Simon D, Korber C, Krausch M, Segering J, Groth P, Gorges R, Grunwald F, Muller-Gartner HW, Schmutzler C, Kohrle J, Roher HD \& Reiners C. Clinical impact of retinoids in redifferentiation therapy of advanced thyroid cancer: final results of a pilot study. European Journal of Nuclear Medicine and Molecular Imaging 200229 775-782.

23 Liu YY, Stokkel MP, Pereira AM, Corssmit EP, Morreau HA, Romijn JA \& Smit JW. Bexarotene increases uptake of radioiodide in metastases of differentiated thyroid carcinoma. European Journal of Endocrinology 2006154 525-531.

24 Kononen J, Bubendorf L, Kallioniemi A, Barlund M, Schraml P, Leighton S, Torhorst J, Mihatsch MJ, Sauter G \& Kallioniemi OP. Tissue microarrays for high-throughput molecular profiling of tumor specimens. Nature Medicine 1998 4 844-847.

25 Toronen P. Selection of informative clusters from hierarchical cluster tree with gene classes. BMC Bioinformatics 2004532.

Received 24 December 2008

Accepted 13 January 2009 